Check for updates

Cite this: RSC Adv., 2017, 7, 55819

Received 4th October 2017

Accepted 1st December 2017

DOI: $10.1039 / c 7 r a 10942 c$

rsc.li/rsc-advances

\section{Synthesis of tetragonal zirconia in mesoporous silica and its catalytic properties for methanol oxidative decomposition $\uparrow$}

\begin{abstract}
Naohiro Shimoda, (D) * Kyoko Nakayama, Keiko Kiyota and Shigeo Satokawa*
The synthesis of zirconia with large specific surface area by the hard template method has been conducted using KIT-6 mesoporous silica. Composite materials of tetragonal zirconia and silica were successfully synthesized by the decomposition of zirconia sources in the mesoporous space of KIT-6, while zirconia in the monoclinic and tetragonal phases was synthesized by the conventional pyrolysis method from the same zirconium sources. The formation behavior of tetragonal zirconia depends on the zirconium source, the pore size of mesoporous silica, the amount of the introduced zirconia source, and the calcination temperature. We conclude that the crystallization of zirconia in the mesoporous space results in the formation of fine zirconia particles (crystallite size effect), leading to the formation of a pure tetragonal zirconia crystal. Furthermore, the nanosized tetragonal zirconia possessing large BET specific surface area was synthesized by removing the silica component in the zirconia-silica composite with alkaline treatment. Additionally, we have evaluated the catalytic performance of tetragonal zirconia materials for methanol oxidative decomposition. Among the zirconia samples synthesized in the present study, the sample prepared by the hard template method and calcined at $800{ }^{\circ} \mathrm{C}$ exhibited the highest activity for methanol oxidation. We deduce that crystallinity of zirconia and high BET specific surface area are necessary to achieve high catalytic activity.
\end{abstract}

\section{Introduction}

Zirconium dioxide $\left(\mathrm{ZrO}_{2}\right)$, known as zirconia, is a material with a high melting point $\left(2700{ }^{\circ} \mathrm{C}\right)$ that exhibits excellent heatresistance, high toughness, abrasion resistance, and chemical resistance, leading to its wide utilization as a ceramic material. Generally, zirconia is produced on an industrial scale by the alkali fusion process using zircon and baddeleyite as zirconium sources. Basically, three crystallite phases of zirconia are wellknown. ${ }^{1}$ The monoclinic phase is stable up to $1170^{\circ} \mathrm{C}$ and is the most common phase. With increasing temperature, the phase transition to the tetragonal phase occurs at $2370{ }^{\circ} \mathrm{C}$ and furthermore, the tetragonal phase changes to the cubic phase at $2680{ }^{\circ} \mathrm{C} .^{2}$ In addition, a metastable tetragonal zirconia is also known and can be stable below $6500^{\circ} \mathrm{C} .{ }^{3,4}$ The volume change of zirconia is quite large at the phase transition induced by the increase in the temperature. By the addition of an impurity such as yttrium oxide and cerium oxide to zirconia, tetragonal and cubic phases are maintained under room temperature, leading

Department of Materials and Life Science, Faculty of Science and Technology, Seikei University, 3-3-1 Kichijoji-kitamachi, Musashino-shi, Tokyo 180-8633, Japan. E-mail: shimoda.naohiro@gmail.com; satokawa@st.seikei.ac.jp; Fax: +81-422-37-3871; Tel: $+81-422-37-3757$

$\dagger$ Electronic supplementary information (ESI) available. See DOI: $10.1039 / \mathrm{c} 7 \mathrm{ra} 10942 \mathrm{c}$ to the improvement of its mechanical properties. ${ }^{5}$ These tetragonal and cubic zirconia materials with several additives are generally called partially stabilized zirconia (PSZ). Furthermore, several processes in which the crystal size is controlled by various techniques were reported for the synthesis of metastable tetragonal zirconia. Garvie reported that metastable tetragonal zirconia can be prepared by the precipitation from alkaline aqueous solution and low temperature calcination of zirconium oxynitrate $;^{3}$ moreover, they proposed that there is a critical crystallite size of zirconia, $c a .30 \mathrm{~nm}$, above which the metastable tetragonal phase could not exist at room temperature. Likewise, Stichert and Schüth reported that tetragonal zirconia with a large surface area of over $100 \mathrm{~m}^{2} \mathrm{~g}^{-1}$ can be synthesized by the calcination at $900{ }^{\circ} \mathrm{C}$ to control the zirconium salt concentration during the precipitation. ${ }^{6}$ In contrast, Inoue $e t$ al. and Kil et al. reported the synthesis of tetragonal zirconia nanoparticles by a glycothermal method. ${ }^{78}$ Furthermore, the sol-gel method, ${ }^{9-13}$ precipitation method using various agents, ${ }^{14-17}$ high temperature hydrolysis method, ${ }^{18,19}$ thermal decomposition process of metal-organic frameworks (MOFs), ${ }^{20}$ hydrothermal method using various template agents, ${ }^{21}$ oil/water interface (emersion) method, ${ }^{22}$ and aqueous gelation method ${ }^{14,23}$ have been reported for the synthesis of the metastable tetragonal zirconia nanoparticles.

Recently, many studies of the synthesis of various metal oxides possessing meso-porosity induced by the hard template 
have been reported. ${ }^{24,25}$ Accordingly, in this work, we focus on the synthesis process in the mesoporous space of mesoporous silica using what we call the "hard-template method" in order to synthesize zirconia with larger specific surface area than the conventional zirconia materials. There are several examples of mesoporous silica materials, for example, 2-D ordered materials, such as KSW-1, FSM-16, MCM-41, and SBA-15, and 3-D ordered ones, such as MCM-48 and KIT- $6 .{ }^{26}$ Among these, the gyroid 3-D cubic Ia $\overline{3} d$ mesoporous silica designated KIT-6 synthesized using a triblock copolymer and butanol mixture in an aqueous solution was reported by Kleitz et al. in 2003. ${ }^{27}$ The structural characteristics, large pore volume and 3-D hexagonal mesostructured of this material are beneficial to the diffusion of substrates and thus the application of a hard template material for the synthesis of nanosized materials; additionally, catalysts and an adsorption material are expected to be obtained using this approach. The studies on the synthesis of the porous zirconia by the hard template method using SBA-15 and polycarbonate membrane ${ }^{28,29}$ and the Zr-KIT6 materials that zirconium is incorporated in the silica framework by the soft template method ${ }^{30}$ were reported by several research groups. Furthermore, Gong et al. reported the synthesis of metastable tetragonal zirconia materials that actually the composite of zirconia and silica $(\mathrm{Si} / \mathrm{Zr}=c a .0 .3$ ) with the modification by an $\mathrm{NaOH}$ solution by the hard template method using SBA-15. ${ }^{31}$ These researchers stated that the stabilization of tetragonal zirconia is due to the confined space of mesoporous silica and the formation of the $\mathrm{Si}-\mathrm{O}-\mathrm{Zr}$ linkages. However, to the best of our knowledge, the synthesis of zirconia introduced in the mesoporous space of KIT- 6 has not been studied. It is also necessary to study the crystallization behavior of pure tetragonal zirconia in more detail.

Furthermore, zirconia are often used both as the sole catalyst and support material, as well as a component of combined catalysts, since zirconia surfaces exhibit acidity and basicity and oxidizing and reducing properties. ${ }^{1}$ In addition to the metastable tetragonal, monoclinic, and tetragonal zirconia and hydrated zirconia that can be applied to a catalyst material have also been reported in the literature. ${ }^{32-35}$ In particular, we reported on the catalytic property of zirconia-supported Ag catalysts for methanol (MeOH) oxidation. ${ }^{32}$

Based on this background, in the present work, the synthesis of zirconia by the hard template method using KIT- 6 have been conducted using various preparation conditions, such as zirconium source, amount of introduced zirconia, calcination temperature, and meso-pore size of silica, and the crystal growth behavior of the synthesized zirconia have been studied. Furthermore, the catalytic property for $\mathrm{MeOH}$ oxidation of the pure zirconia have been evaluated after the removal of the silica component.

\section{Experimental}

\section{Synthesis procedure of samples}

Mesoporous silica and non-porous silica. Mesoporous silica KIT-6 samples used in this work were synthesized as previously reported. ${ }^{27}$ In a typical beaker, Pluronic P123 $\left(\mathrm{EO}_{20} \mathrm{PO}_{70} \mathrm{EO}_{20}\right.$,
$\mathrm{MW}=5750, \mathrm{BASF}$ ) was dissolved in a mixture of $35 \%$ to $37 \%$ $\mathrm{HCl}$ (Wako Chemical Industries) and distilled water, and the solution was stirred at $35{ }^{\circ} \mathrm{C}$ for $2 \mathrm{~h}$. Next, 99.4\% 1-butanol (Sigma-Aldrich) was added into the solution. After stirring for $2 \mathrm{~h}, 3 \mathrm{~N}$-tetraethoxysilane (TEOS, Kanto Chemical) was added into the mixture, and the mixture was stirred at $35{ }^{\circ} \mathrm{C}$ for $24 \mathrm{~h}$. Next, the mixture was heated in air at $100{ }^{\circ} \mathrm{C}$ for $24 \mathrm{~h}$ under static conditions in a closed plastic bottle, meaning that a hydrothermal treatment was employed. The obtained product was washed and filtered and was dried in air at $50{ }^{\circ} \mathrm{C}$. Finally, the powder product was obtained as KIT- 6 by the calcination in air at $550{ }^{\circ} \mathrm{C}$ for $6 \mathrm{~h}$.

For comparing another silica material to KIT-6, we synthesized spherical silica without meso-pores by the Stöber method. ${ }^{36}$ A mixture of ethanol, TEOS, and distilled water was stirred for $10 \mathrm{~min}$ at room temperature. Next, $2.25 \mathrm{~mL}$ of $28 \%$ ammonia aqueous (Wako Chemical Industries) was added three times every $30 \mathrm{~min}$ to the mixture, and the mixture was stirred for $1 \mathrm{~h}$. The obtained product was dried in air at $110{ }^{\circ} \mathrm{C}$ and was finally calcined in air at $550{ }^{\circ} \mathrm{C}$ for $6 \mathrm{~h}$; thereafter, this synthesized non-porous silica was denoted as "S". In contrast, commercial silica samples with non-ordered meso-pores and various pore sizes were also provided by FUJI SILYSIA CHEMICAL, denoted as Q-3, Q-10, Q-30, and Q-50, respectively.

Composite of zirconia and silica. Zirconyl nitrate dihydrate $\left(\mathrm{ZrO}\left(\mathrm{NO}_{3}\right)_{2} \cdot 2 \mathrm{H}_{2} \mathrm{O}\right.$, Wako Chemical Industries) and $70 \mathrm{wt} \%$ zirconium propoxide solution in 1-propanol $\left(\mathrm{Zr}\left(\mathrm{OCH}_{2} \mathrm{CH}_{2}\right.\right.$ $\left.\mathrm{CH}_{3}\right)_{4}$, Sigma-Aldrich) was employed as the zirconium source. Each silica sample synthesized and obtained was mixed with distilled water in an eggplant flask followed by the addition of a predetermined amount of each zirconium source. The mixture solution was stirred in a water bath at $50{ }^{\circ} \mathrm{C}$ under $26 \mathrm{kPa}$ and was heated to $70{ }^{\circ} \mathrm{C}$, and then the pressure was reduced to 21 $\mathrm{kPa}$ in order to evaporate a solvent sufficiently. Finally, the sample was calcined in air at various temperatures for $4 \mathrm{~h}$, and the composite product of zirconium and silica (zirconia/silica composite, $\mathrm{ZrO}_{2} / \mathrm{SiO}_{2}$ ) was obtained. Subsequently, the composites synthesized from zirconyl nitrate (N) and zirconium propoxide (P) using KIT-6 (K) or non-porous silica (S) were denoted as $\mathrm{ZXN} / \mathrm{K}(T), \mathrm{ZXP} / \mathrm{K}(T), \mathrm{ZXN} / \mathrm{S}(T)$, and $\mathrm{ZXP} / \mathrm{S}(T)$, respectively, where $X$ and $T$ represent the fraction of the introduced zirconia of the composite, $\mathrm{ZrO}_{2} /\left(\mathrm{ZrO}_{2}+\mathrm{SiO}_{2}\right): 20 \mathrm{wt} \%$, $50 \mathrm{wt} \%$, and $80 \mathrm{wt} \%$; and the calcination temperature: $400{ }^{\circ} \mathrm{C}$, $600{ }^{\circ} \mathrm{C}$, and $800{ }^{\circ} \mathrm{C}$; respectively.

Furthermore, the $\mathrm{ZrO}_{2} / \mathrm{SiO}_{2}$ composites were synthesized using Q-3, Q-10, Q-30, and Q-50 as the silica template and zirconyl nitrate as the zirconium source with the $20 \mathrm{wt} \%$ and $50 \mathrm{wt} \%$ amount of introduced zirconia. All composites were finally calcined at $600{ }^{\circ} \mathrm{C}$ and were denoted as the $\mathrm{Z} 20 \mathrm{~N} / \mathrm{Q}-M$ and Z50N/Q- $M(M=3,10,30,50)$.

Removal of silica component. The pure zirconia for which the silica component was removed was obtained by the alkaline treatment: the synthesized $\mathrm{Z} 50 \mathrm{~N} / \mathrm{K}(T)$ samples were treated at $50{ }^{\circ} \mathrm{C}$ for $16 \mathrm{~h}$ in $2 \mathrm{M} \mathrm{KOH}$ (Wako Pure Chemical Industries) solution (denoted as $\operatorname{tZN}(T)$ ).

In addition, reference zirconia samples were synthesized by the thermal decomposition method, that is, by the calcination 
of the zirconium nitrate and zirconium propoxide as zirconium sources in air for $4 \mathrm{~h}$. The synthesized samples were denoted as $\operatorname{rZN}(T)$ and $\operatorname{rZP}(T)$, respectively.

\section{Sample characterization}

The physical properties of each sample were evaluated by $\mathrm{N}_{2}$ adsorption isotherm at $-196{ }^{\circ} \mathrm{C}$ using a MicrotracBEL BELSORP-mini II instrument. Prior to $\mathrm{N}_{2}$ adsorption and desorption measurement, the sample was degassed at $150{ }^{\circ} \mathrm{C}$ for $2 \mathrm{~h}$ in order to remove the moisture adsorbed on the surface and inside the porous network. The Brunauer-Emmett-Teller (BET) method was used to estimate the specific surface area $\left(S_{\mathrm{BET}}\right)$ from the obtained adsorption data. Total pore volume $\left(V_{\text {pore }}\right.$ ) was estimated from the amount of $\mathrm{N}_{2}$ adsorbed at $P / P_{0}=$ 0.99. The Barrett-Joyner-Halenda $(\mathrm{BJH})$ method was used to evaluate the pore size distribution and to determine the pore volume $\left(V_{\text {meso-pore }}\right)$ and pore diameter peaks of meso-pores $\left(d_{\text {meso-pore }}\right)$, which are above $0.01 \mathrm{~d} V / \mathrm{d} d \mathrm{~cm}^{3} \mathrm{~g}^{-1} \mathrm{~nm}^{-1}$, from the adsorption branch of the $\mathrm{N}_{2}$ adsorption isotherm.

To estimate the chemical composition of the synthesized sample, the inductively coupled plasma atomic emission spectroscopy (ICP-AES) analysis was performed using a Shimadzu ICPS-7500 instrument. Sulfuric acid and fluoric acid were used to dissolve each sample.

To identify the crystalline structure of each sample, the powder X-ray diffraction (XRD) patterns were measured using a Rigaku Ultima IV instrument equipped with a $\mathrm{Cu} \mathrm{K} \alpha$ radiation source $(\lambda=0.154 \mathrm{~nm})$. The typical working conditions such as the acceleration voltage and current were $40 \mathrm{kV}$ and $40 \mathrm{~mA}$ with the scanning speed of $1^{\circ} \mathrm{min}^{-1}$. The crystallite size $(D)$ of the zirconia phase was estimated from the diffraction peak using Scherrer's equation as follows:

$$
D=\frac{K \lambda}{\beta \cos \theta}
$$

where $K$ is the shape factor $(0.89), \lambda$ is the X-ray wavelength $(0.154 \mathrm{~nm}), \beta$ is the line broadening at half the maximum intensity in radians, and $\theta$ is the Bragg angle.

Raman spectra of the synthesized samples were measured using a HORIBA JOBIN YVON equipped with a CCD camera and a $514 \mathrm{~nm}$ Ar laser.

Transmission electron microscopy (TEM) observation for each sample was performed using a JEOL JEM-2100F instrument operated at $200 \mathrm{kV}$. Each sample was crushed into powder and dispersed in ethanol with ultrasonic vibration and was subsequently transferred to a standard $\mathrm{Cu}$ grid covered with a holey carbon film.

\section{Evaluation of catalytic activity for $\mathrm{MeOH}$ oxidation}

Catalytic activity tests of $\mathrm{MeOH}$ oxidation over the synthesized zirconia were carried out in a fixed bed flow reactor under atmospheric pressure. Each synthesized zirconia (100 mg) was housed in a quartz reactor (i.d. $6 \mathrm{~mm}$ ) and a reaction gas mixture (1000 ppm MeOH/20\% $\mathrm{O}_{2} / \mathrm{Ar}$ ) was fed into the catalyst bed at the total flow rate of $c a .250 \mathrm{~mL} \mathrm{~min}{ }^{-1}$. The ratio of weight of catalyst to the flow rate $(\mathrm{W} / \mathrm{F})$ was $c a .6 .7 \mathrm{~g}_{\text {cat. }} \mathrm{h}$ $\mathrm{L}_{\mathrm{MeOH}}{ }^{-1}$. The compositions of the influent and effluent gases were analyzed using a gas chromatograph equipped with a flame ionization detector (GC-FID, Shimadzu, GC-8A) after the separation of gaseous products by a BX-10 column (GL Science).

\section{Results and discussion}

\section{Synthesis of $\mathrm{ZrO}_{2} / \mathrm{SiO}_{2}$ composite}

Effect of porosity of silica. First, we have studied the effect of meso-pores of silica used for the synthesis of the $\mathrm{ZrO}_{2} / \mathrm{SiO}_{2}$ composite. The textural properties of the synthesized silica and the $\mathrm{ZrO}_{2} / \mathrm{SiO}_{2}$ composites determined from $\mathrm{N}_{2}$ adsorption measurement are summarized in Table 1 . The $S_{\mathrm{BET}}$ of nonporous silica (S) synthesized by the Stöber method was $28 \mathrm{~m}^{2} \mathrm{~g}^{-1}$, and its values of $V_{\text {pore }}$ and $V_{\text {meso-pore }}$ were

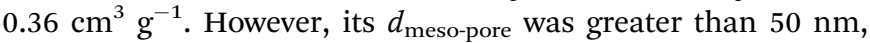
indicating the over-evaluation of meso-pore volume by the $\mathrm{BJH}$ method. We thus consider that there were almost no mesopores in the non-porous silica (S) synthesized in this work. In contrast, $S_{\mathrm{BET}}, V_{\text {pore }}, V_{\text {meso-pore, }}$ and $d_{\text {meso-pore }}$ of mesoporous KIT-6 (K) were $840 \mathrm{~m}^{2} \mathrm{~g}^{-1}, 1.13 \mathrm{~cm}^{3} \mathrm{~g}^{-1}, 1.02 \mathrm{~cm}^{3} \mathrm{~g}^{-1}$, and $8.1 \mathrm{~nm}$, respectively. Using each silica sample, we synthesized the $\mathrm{ZrO}_{2} / \mathrm{SiO}_{2}$ composites from zirconyl nitrate at $20 \mathrm{wt} \%$ amount of introduced zirconia. The composite synthesized using the Stöber silica (Z20N/S(600)) exhibited $S_{\text {BET }}$ of $19 \mathrm{~m}^{2} \mathrm{~g}^{-1}$, $V_{\text {pore }}$ of $0.10 \mathrm{~cm}^{3} \mathrm{~g}^{-1}$, and $V_{\text {meso-pore }}$ of $0.11 \mathrm{~cm}^{3} \mathrm{~g}^{-1}$, respectively. Additionally, in the case of the composite synthesized using porous silica (Z20N/K(600)), its $S_{\mathrm{BET}}, V_{\text {pore }}$, and $V_{\text {meso-pore }}$ were $567 \mathrm{~m}^{2} \mathrm{~g}^{-1}, 0.85 \mathrm{~cm}^{3} \mathrm{~g}^{-1}$, and $0.82 \mathrm{~cm}^{3} \mathrm{~g}^{-1}$, respectively. The $d_{\text {meso-pore }}$ of $\mathrm{Z} 20 \mathrm{~N} / \mathrm{K}(600)$ was similar to that of KIT-6.

Fig. 1 shows the XRD patterns of non-porous and porous silica samples and their composite samples with zirconia. The diffraction pattern of the commercial zirconia, JRC-ZRO-3 (Japan Reference Catalyst, Catalysis Society of Japan) used as

Table 1 Physical properties of the non-porous silica, meso-porous silica, $\mathrm{ZrO}_{2} / \mathrm{SiO}_{2}$ composites

\begin{tabular}{lclcc}
\hline Sample & $S_{\mathrm{BET}}{ }^{a} / \mathrm{m}^{2} \mathrm{~g}^{-1}$ & $V_{\text {pore }}{ }^{b} / \mathrm{cm}^{3} \mathrm{~g}^{-1}$ & $V_{\text {meso-pore }}^{c} / \mathrm{cm}^{3} \mathrm{~g}^{-1}$ & 0.36 \\
\hline Non-porous $\mathrm{SiO}_{2}(\mathrm{~S})$ & 28 & 0.36 & 1.02 & $>50$ \\
KIT-6 (K) & 840 & 1.13 & 0.11 & 8.1 \\
$\mathrm{Z} 20 \mathrm{~N} / \mathrm{S}(600)$ & 19 & 0.10 & 0.82 & $>50$ \\
$\mathrm{Z} 20 \mathrm{~N} / \mathrm{K}(600)$ & 567 & 0.85 & 8.2
\end{tabular}

${ }^{a}$ BET specific surface area. ${ }^{b}$ Total pore volume: estimated at $0.99 P / P_{0} .{ }^{c}$ Pore volume of meso-pores: estimated by the BJH method. ${ }^{d}$ Major mesopore diameter peaks: estimated from adsorption branch by the BJH method. 


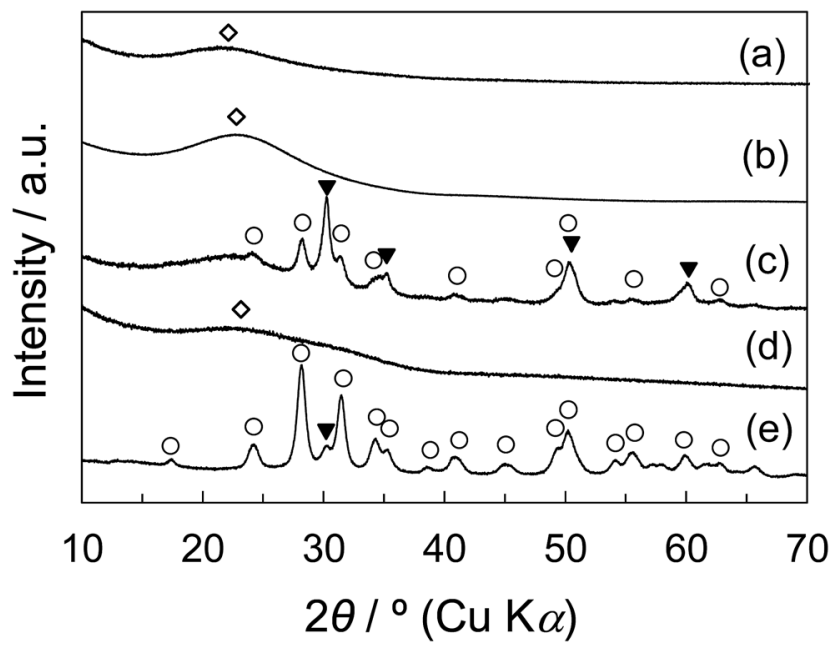

Fig. 1 Wide-angle XRD patterns of (a) non-porous $\mathrm{SiO}_{2}(\mathrm{~S})$ synthesized by the Stöber method, (b) meso-porous KIT-6 (K), (c) Z20N/S(600), (d) $\mathrm{Z2ON} / \mathrm{K}(600)$, and (e) reference $\mathrm{ZrO}_{2}$ (JRC-ZRO-3): (O) $\mathrm{ZrO}_{2}-$ monoclinic, $(\boldsymbol{\nabla}) \mathrm{ZrO}_{2}$-tetragonal, $(\diamond) \mathrm{SiO}_{2}$.

the reference zirconia was also shown. The crystalline phase of zirconia at $600{ }^{\circ} \mathrm{C}$ is generally known to be the mixture of metastable tetragonal and monoclinic phases. Indeed, JRCZRO-3 primarily exhibited the monoclinic phase and partially tetragonal phase, as shown in Fig. 1e. For the $\mathrm{Z} 20 \mathrm{~N} / \mathrm{S}(600)$, the diffraction peaks corresponding to tetragonal and monoclinic phases were observed (Fig. 1c). On the other hand, as shown in Fig. 1d, the only broad diffraction peak attributed to KIT-6 was observed for $\mathrm{Z} 20 \mathrm{~N} / \mathrm{K}(600)$, indicating that zirconia is either in amorphous state or consists of microcrystal particles. We consider that the existence of meso-pore in the silica significantly affects the difference in the crystallization behavior of zirconium component to zirconia.

Effect of zirconium source. We have studied the difference in the zirconium source used for the synthesis of the $\mathrm{ZrO}_{2} / \mathrm{SiO}_{2}$ composite. Fig. 2 shows the $\mathrm{N}_{2}$ adsorption and desorption isotherms (A) and the pore size distribution (BJH plot) (B) of the synthesized KIT- 6 and the $\mathrm{ZrO}_{2} / \mathrm{SiO}_{2}$ composites synthesized from zirconium propoxide $(\mathrm{Z} 50 \mathrm{P} / \mathrm{K}(600))$ and zirconyl nitrate $(\mathrm{Z} 50 \mathrm{~N} / \mathrm{K}(600))$ as the zirconium source with the $50 \mathrm{wt} \%$ introduced amount of zirconia. All the samples exhibited the type IV(a) isotherms with an $\mathrm{H} 1$ hysteresis loop, indicating their mesoporous structure. In addition, $S_{\mathrm{BET}}, V_{\text {pore }}, V_{\text {meso-pore }}$, and $d_{\text {meso-pore }}$ determined from the $\mathrm{N}_{2}$ adsorption measurement and weight fraction of zirconia content obtained by the ICP-AES analysis of the synthesized composites as well as KIT-6, $\operatorname{rZP}(600)$, and $\operatorname{rZN}(600)$ are summarized in Table 2. The $V_{\text {pore }}$ of $\mathrm{Z} 50 \mathrm{P} / \mathrm{K}(600)$ and $\mathrm{Z} 50 \mathrm{~N} / \mathrm{K}(600)$ were $0.38 \mathrm{~cm}^{3} \mathrm{~g}^{-1}$ and $0.41 \mathrm{~cm}^{3} \mathrm{~g}^{-1}$,

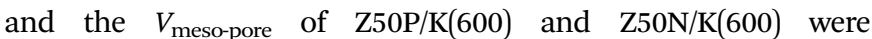
$0.32 \mathrm{~cm}^{3} \mathrm{~g}^{-1}$ and $0.38 \mathrm{~cm}^{3} \mathrm{~g}^{-1}$, respectively. The $\mathrm{ZrO}_{2}$ weight ratios of the synthesized both $\mathrm{ZrO}_{2} / \mathrm{SiO}_{2}$ composites were $57 \mathrm{wt} \%$. Furthermore, two peaks appeared at $3.7 \mathrm{~nm}$ and $7.2 \mathrm{~nm}$ for $\mathrm{Z} 50 \mathrm{P} /$ $\mathrm{K}(600)$ composite, implying the existence of two pores with different sizes. The original KIT-6 silica template possessed $1.13 \mathrm{~cm}^{3} \mathrm{~g}^{-1}$ of $V_{\text {pore }}$ and $1.02 \mathrm{~cm}^{3} \mathrm{~g}^{-1}$ of $V_{\text {meso-pore, }}$, respectively.
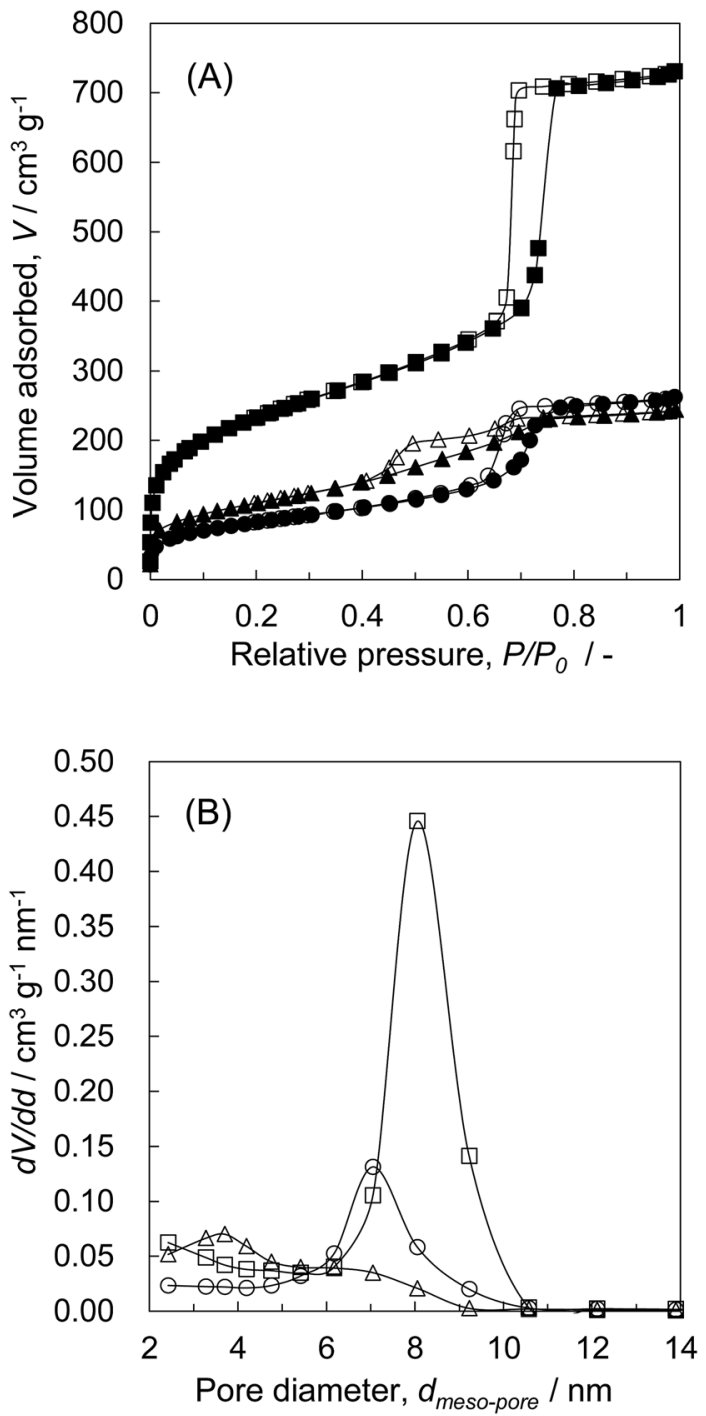

Fig. 2 (A) $\mathrm{N}_{2}$ adsorption and desorption isotherms and (B) pore size distribution plots by the $\mathrm{BJH}$ method of $(\boldsymbol{\square}, \square) \mathrm{KIT}-6$ and $\mathrm{ZrO}_{2} / \mathrm{SiO}_{2}$ composites of $(\boldsymbol{\Lambda}, \triangle) Z 50 \mathrm{P} / \mathrm{K}(600)$-propoxide and $(\bullet, \mathrm{O}) \mathrm{Z50N} /$ K(600)-nitrate: (solid symbol) adsorption branch, (open symbol) desorption branch.

Thus, we consider that this finding is observed because that the formation of zirconia particles is affected by the differences in a zirconium source and a solvent during the preparation procedure. The $S_{\mathrm{BET}}$ of $\mathrm{rZP}(600)$ and $\operatorname{rZN}(600)$, which were synthesized by the thermal decomposition method, were below $1 \mathrm{~m}^{2} \mathrm{~g}^{-1}$ and $32 \mathrm{~m}^{2} \mathrm{~g}^{-1}$, respectively. In addition, the $V_{\text {meso-pore }}$ of them were $0.02 \mathrm{~cm}^{3} \mathrm{~g}^{-1}$ and $0.26 \mathrm{~cm}^{3} \mathrm{~g}^{-1}$, which were nearly identical to their $V_{\text {pore }}$ values.

The XRD patterns of $\mathrm{Z} 50 \mathrm{P} / \mathrm{K}(600), \mathrm{Z} 50 \mathrm{~N} / \mathrm{K}(600), \operatorname{rZP}(600)$, and $\mathrm{rZN}(600)$ are shown in Fig. 3. It was observed that the zirconia samples synthesized by the thermal decomposition method from zirconium propoxide and zirconyl nitrate as zirconium sources consist of monoclinic and tetragonal phases. For the rZN(600), the diffraction peaks assigned to the tetragonal phase were observed slightly and the peaks assigned to monoclinic phase were mainly observed. For the Z50P/K(600), 
Table 2 Physical properties of the $\mathrm{ZrO}_{2} / \mathrm{SiO}_{2}$ composites and reference zirconia

\begin{tabular}{|c|c|c|c|c|c|}
\hline Sample & $S_{\mathrm{BET}}^{a} / \mathrm{m}^{2} \mathrm{~g}^{-1}$ & $V_{\text {pore }}^{b} / \mathrm{cm}^{3} \mathrm{~g}^{-1}$ & $V_{\text {meso-pore }} / \mathrm{cm}^{3} \mathrm{~g}^{-1}$ & $d_{\text {meso-pore }}{ }^{d} / \mathrm{nm}$ & $\mathrm{ZrO}_{2} /\left(\mathrm{ZrO}_{2}+\mathrm{SiO}_{2}\right)^{e} / \mathrm{wt} \%$ \\
\hline $\mathrm{Z} 50 \mathrm{P} / \mathrm{K}(600)$ & 392 & 0.38 & 0.32 & $3.7,7.1$ & 57 \\
\hline $\mathrm{Z} 50 \mathrm{~N} / \mathrm{K}(600)$ & 295 & 0.41 & 0.38 & 7.1 & 45 \\
\hline $\operatorname{rZN}(600)$ & 32 & 0.26 & 0.26 & $>50$ & 100 \\
\hline
\end{tabular}

${ }^{a}$ BET specific surface area. ${ }^{b}$ Total pore volume: estimated at $0.99 P / P_{0} \cdot{ }^{c}$ Pore volume of meso-pores: estimated by the BJH method. ${ }^{d}$ Major mesopore diameter peaks: estimated from adsorption branch by the BJH method. ${ }^{e}$ Weight ratio: estimated by the ICP-AES analysis.

the formation of zirconia with monoclinic and tetragonal phases were confirmed, while tetragonal phase was found to be the main crystalline phase. In contrast, the broad diffraction peaks appeared at $2 \theta=c a .30^{\circ}$ and $c a .50^{\circ}$ for the $\mathrm{Z} 50 \mathrm{~N} / \mathrm{K}(600)$. It is presumably considered that the zirconia components are mainly amorphous and slightly tetragonal. These results revealed that the crystal growth behavior of zirconia differs depending on the zirconium source. The crystalline phase of $\mathrm{Z} 50 \mathrm{~N} / \mathrm{K}(600)$ was solely tetragonal and because of this the zirconia crystal can be formed in the meso-porous space of KIT6. The pore size of KIT- 6 was $c a$. $8.1 \mathrm{~nm}$, and thus, the space in which zirconia crystal can be grown is limited from reaching the meso size. Garvie et al. reported that when the zirconia particle size is below $30 \mathrm{~nm}$, the zirconia after the calcination below $1170{ }^{\circ} \mathrm{C}$ can be theoretically found in the tetragonal phase. ${ }^{3,4} \mathrm{As}$ in the present case, tetragonal zirconia is considered to be predominantly formed because the crystal growth of zirconia particles was limited below $30 \mathrm{~nm}$.

Effect of calcination temperature. We have studied the effect of calcination temperature for the synthesis of the $\mathrm{ZrO}_{2} / \mathrm{SiO}_{2}$ composite. There is a possibility that the KIT-6 structure will

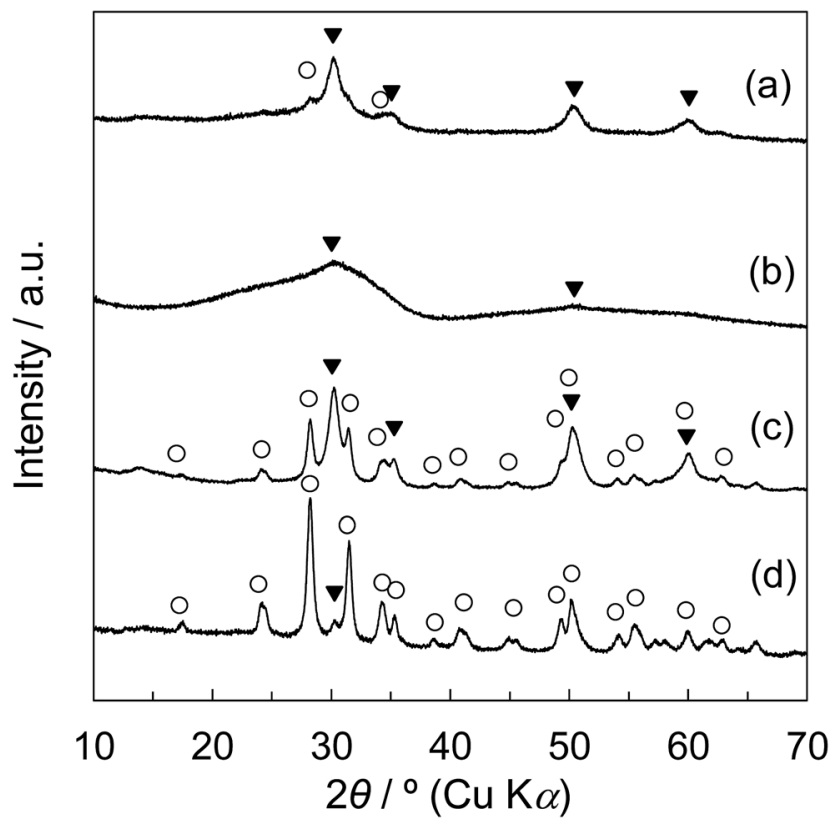

Fig. 3 Wide-angle XRD patterns of (a) Z50P/K(600)-propoxide, (b) Z50N/K(600)-nitrate, (c) $r Z P(600)$, and (d) $r Z N(600)$ : (O) $\mathrm{ZrO}_{2}$ monoclinic, ( $\boldsymbol{\nabla}) \mathrm{ZrO}_{2}$-tetragonal. change the final calcination; therefore, the calcination temperature dependence on the physical properties of KIT- 6 has been studied. As summarized in Table S1, $\dagger$ the $S_{\mathrm{BET}}, V_{\mathrm{pore}}$, and $V_{\text {meso-pore }}$ of KIT-6 samples with the calcination at $600{ }^{\circ} \mathrm{C}$ and $800{ }^{\circ} \mathrm{C}$ for $4 \mathrm{~h}$ were smaller than those without and with the calcination at $400{ }^{\circ} \mathrm{C}$. The $d_{\text {meso-pore }}$ of the KIT-6 samples calcined at $800{ }^{\circ} \mathrm{C}$ decreased to $c a .7 .2 \mathrm{~nm}$. Furthermore, based on the small-angle X-ray scattering (SAXS) analysis of each KIT-6 sample (Fig. S1 $\dagger$ ), it was found that the peak assigned to the (211) plane shifted to a higher angle with the increase in the calcination temperature and the $I a \overline{3} d$ structure of KIT- 6 was retained after the calcination at $800{ }^{\circ} \mathrm{C}$. Therefore, for the synthesis of the $\mathrm{ZrO}_{2} / \mathrm{SiO}_{2}$ composites, while $S_{\mathrm{BET}}, V_{\text {pore }}$, $V_{\text {meso-pore }}$, and $d_{\text {meso-pore }}$ are decreased to a certain extent, the mesoporous structure of KIT- 6 is considered to be maintained after the high temperature calcination at $800{ }^{\circ} \mathrm{C}$.

The $\mathrm{ZrO}_{2} / \mathrm{SiO}_{2}$ composites were synthesized from KIT- 6 and from zirconium propoxide or zirconium nitrate as zirconia sources by the $50 \mathrm{wt} \%$ of the introduced amount, followed by the final calcination at $400{ }^{\circ} \mathrm{C}, 600{ }^{\circ} \mathrm{C}$, and $800{ }^{\circ} \mathrm{C}$ (denoted as $\mathrm{Z} 50 \mathrm{P} / \mathrm{K}(T)$ and $\mathrm{Z} 50 \mathrm{~N} / \mathrm{K}(T))$. The physical properties of the synthesized composites are summarized in Table 3. As mentioned above, the $\mathrm{ZrO}_{2} / \mathrm{SiO}_{2}$ composites $(\mathrm{Z} 50 \mathrm{P} / \mathrm{K}(T)$ ) synthesized from zirconium propoxide with various calcination temperatures showed two mesopore peaks in each $\mathrm{BJH}$ plot. The $S_{\mathrm{BET}}, \quad V_{\text {pore }}$, and $V_{\text {meso-pore }}$ of $\mathrm{Z} 50 \mathrm{P} / \mathrm{K}(T)$ decreased with increasing calcination temperature. This may be due to the shrinkage of KIT- 6 and the grain growth of zirconia. In contrast, for the $\mathrm{ZrO}_{2} / \mathrm{SiO}_{2}$ composites $(\mathrm{Z} 50 \mathrm{~N} / \mathrm{K}(T)$ ) synthesized from zirconium nitrate at $400{ }^{\circ} \mathrm{C}, 600{ }^{\circ} \mathrm{C}$, and $800{ }^{\circ} \mathrm{C}$, their $d_{\text {meso-pore }}$ were $8.2 \mathrm{~nm}, 7.1 \mathrm{~nm}$, and $7.2 \mathrm{~nm}$, respectively. As discussed in the above section, the crystal growth behavior of zirconia in KIT6 is considered to be influenced by the zirconia source and the used solvent.

Fig. $4 \mathrm{a}$ and $\mathrm{b}$ show the XRD patterns of $\mathrm{Z} 50 \mathrm{P} / \mathrm{K}(T)$ and Z50N/ $\mathrm{K}(T)$ with various calcination temperatures. For the Z50P/ $\mathrm{K}(400)$, only the peaks corresponding to the tetragonal phase of zirconia appeared, whereas for the $\mathrm{Z50P} / \mathrm{K}(600$ and 800$)$, the diffraction peaks assigned to monoclinic phase were also observed. The rZP(600) synthesized by the thermal decomposition method was composed of monoclinic and tetragonal phases as shown in Fig. 3c, indicating that the crystallization of the zirconium component outside the mesoporous space of KIT- 6 results in the formation of the mixed crystal zirconia. Therefore, a part of zirconia was considered to be crystallized on the outside of the mesoporous space of the silica for the $\mathrm{Z} 50 \mathrm{P} /$ 
Table 3 Physical properties of the $\mathrm{ZrO}_{2} / \mathrm{SiO}_{2}$ composites of $\mathrm{Z50P} / \mathrm{K}(T)$ and $\mathrm{ZXN} / \mathrm{K}(T): X=20,50,80, T=400,600,800$

\begin{tabular}{|c|c|c|c|c|c|}
\hline Sample & $S_{\mathrm{BET}}{ }^{a} / \mathrm{m}^{2} \mathrm{~g}^{-1}$ & $V_{\text {pore }}^{b} / \mathrm{cm}^{3} \mathrm{~g}^{-1}$ & $V_{\text {meso-pore }}{ }^{c} / \mathrm{cm}^{3} \mathrm{~g}^{-1}$ & $d_{\text {meso-pore }}{ }^{d} / \mathrm{nm}$ & $\mathrm{ZrO}_{2} /\left(\mathrm{ZrO}_{2}+\mathrm{SiO}_{2}\right)^{e} / \mathrm{wt} \%$ \\
\hline Z50P/K(400) & 492 & 0.46 & 0.38 & $3.7,7.2$ & 57 \\
\hline $\mathrm{Z} 50 \mathrm{P} / \mathrm{K}(600)$ & 392 & 0.38 & 0.32 & $3.7,7.2$ & 57 \\
\hline Z50N/K(400) & 407 & 0.53 & 0.44 & 8.2 & 48 \\
\hline Z50N/K(600) & 295 & 0.41 & 0.38 & 7.1 & 45 \\
\hline $\mathrm{Z50N/K}(800)$ & 299 & 0.40 & 0.38 & 7.2 & 47 \\
\hline $\mathrm{Z} 20 \mathrm{~N} / \mathrm{K}(800)$ & 458 & 0.70 & 0.67 & 7.2 & 22 \\
\hline $\mathrm{Z} 80 \mathrm{~N} / \mathrm{K}(400)$ & 240 & 0.49 & 0.49 & $4.8,9.2$ & 85 \\
\hline Z80N/K(600) & 226 & 0.41 & 0.41 & $4.8,8.1$ & 83 \\
\hline Z80N/K(800) & 221 & 0.32 & 0.32 & $4.2,6.2$ & 83 \\
\hline
\end{tabular}

${ }^{a}$ BET specific surface area. ${ }^{b}$ Total pore volume: estimated at $0.99 P / P_{0} \cdot{ }^{c}$ Pore volume of meso-pore: estimated by the BJH method. ${ }^{d}$ Major mesopore diameter peaks: estimated from adsorption branch by the BJH method. ${ }^{e}$ Weight ratio: estimated by the ICP-AES analysis.

$\mathrm{K}(600$ and 800$)$. However, it is important to note that the crystallization behavior of zirconia for the $\mathrm{Z} 50 \mathrm{~N} / \mathrm{K}(T)$ was quite unique in comparison to the cases for the other samples. As shown in Fig. $4 \mathrm{~b}$, the broad peak was observed at $2 \theta=c a .30^{\circ}$ for the $\mathrm{Z} 50 \mathrm{~N} / \mathrm{K}(400)$ for the final calcination at $400{ }^{\circ} \mathrm{C}$, implying that the zirconia was in the amorphous state. With increasing calcination temperature, the peak attributed to the tetragonal phase gradually appeared, and it was observed that the Z50N/ $\mathrm{K}(800)$ consisted of only tetragonal zirconia even after the final calcination at $800{ }^{\circ} \mathrm{C}$.

Effect of the amount of introduced zirconium component. We have also studied the effect of amount of introduced zirconium nitrate as the zirconium source for the $\mathrm{ZrO}_{2} / \mathrm{SiO}_{2}$ composites synthesis. The physical properties of $\mathrm{Z} 20 \mathrm{~N} / \mathrm{K}(T)$ and
$\mathrm{Z} 80 \mathrm{~N} / \mathrm{K}(T)$ composites with the $20 \mathrm{wt} \%$ and $80 \mathrm{wt} \%$ amounts of introduced zirconia are summarized in Table 3. Upon increasing the zirconium content, the $S_{\mathrm{BET}}, V_{\text {pore }}$, and $V_{\text {meso-pore }}$ of each composite were decreased, and there was a similar tendency for the $\mathrm{Z} 50 \mathrm{~N} / \mathrm{K}(T)$ and $\mathrm{Z} 50 \mathrm{P} / \mathrm{K}(T)$ composites regarding the effect of final calcination temperature. Based on the ICP-AES analysis for each composite, there was almost no difference in the amount of introduced zirconia component between the synthesized composites. Furthermore, the XRD patterns of $\mathrm{Z} 20 \mathrm{~N} / \mathrm{K}(T)$ and $\mathrm{Z} 80 \mathrm{~N} / \mathrm{K}(T)$ are shown in Fig. 4c and d. For the $\mathrm{Z} 20 \mathrm{~N} / \mathrm{K}(T)$ composites, the broad diffraction peak attributed to the $\mathrm{SiO}_{2}$ phase and the amorphous zirconia phase were observed at $2 \theta=c a .22^{\circ}$ and $c a .30^{\circ}$, respectively. For Z20N/ $\mathrm{K}(800)$, the tetragonal phase of zirconia was observed slightly.
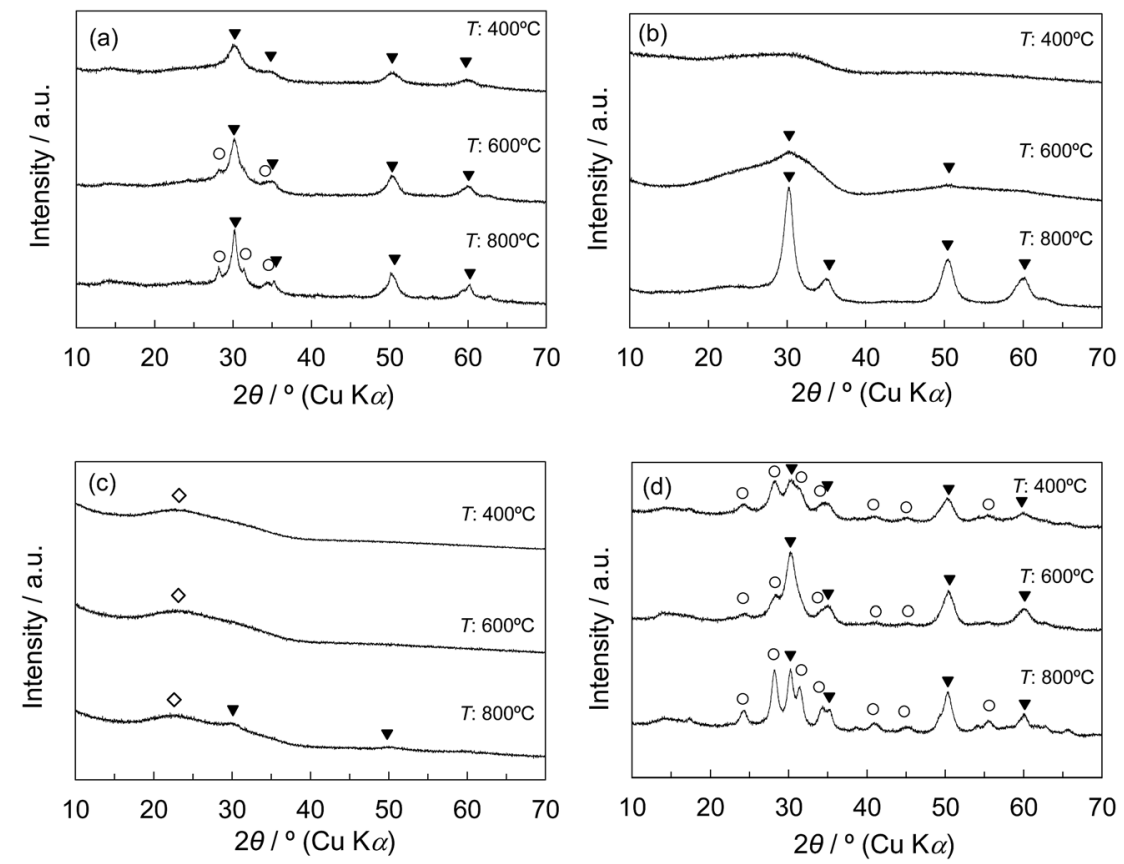

Fig. 4 Effect of calcination temperature of $\mathrm{ZrO}_{2} / \mathrm{SiO}_{2}$ composites on XRD patterns: (a) Z50P/K(T), (b) Z50N/K(T), (c) Z20N/K(T), (d) Z80N/K(T); $T$ $=400,600,800:(O) \mathrm{ZrO}_{2}$-monoclinic, $(\boldsymbol{\nabla}) \mathrm{ZrO}_{2}$-tetragonal, $(\diamond) \mathrm{SiO}_{2}$. 
Table 4 Physical properties of the $\mathrm{ZrO}_{2} / \mathrm{SiO}_{2}$ composites using Q-M mesoporous silica: $M=3,10,30,50$

\begin{tabular}{|c|c|c|c|c|c|}
\hline Sample & $S_{\mathrm{BET}}{ }^{a} / \mathrm{m}^{2} \mathrm{~g}^{-1}$ & $V_{\text {pore }}^{b} / \mathrm{cm}^{3} \mathrm{~g}^{-1}$ & $V_{\text {meso-pore }} / \mathrm{cm}^{3} \mathrm{~g}^{-1}$ & $d_{\text {meso-pore }} d / \mathrm{nm}$ & $\mathrm{ZrO}_{2} /\left(\mathrm{ZrO}_{2}+\mathrm{SiO}_{2}\right)^{e} / \mathrm{wt} \%$ \\
\hline Q-3 & 725 & 0.45 & 0.26 & $<2$ & - \\
\hline Q-10 & 315 & 1.35 & 1.33 & $7.1,12.1,16.0,21.3$ & - \\
\hline Q-50 & 73 & 1.16 & 1.16 & 78.0 & - \\
\hline Z20N/Q-3 & 352 & 0.23 & 0.16 & $<2$ & 21 \\
\hline Z20N/Q-10 & 253 & 0.93 & 0.92 & $8.1,12.1,16.0,24.5$ & 22 \\
\hline Z50N/Q-3 & 298 & 0.25 & 0.21 & $<2$ & 57 \\
\hline Z50N/Q-10 & 215 & 0.57 & 0.56 & $6.2,10.6$ & 55 \\
\hline Z50N/Q-30 & 109 & 0.59 & 0.59 & $10.6,13.9,44.1$ & 55 \\
\hline Z50N/Q-50 & 77 & 0.51 & 0.51 & 21.3 & 55 \\
\hline
\end{tabular}

${ }^{a}$ BET specific surface area. ${ }^{b}$ Total pore volume: estimated at $0.99 P / P_{0} \cdot{ }^{c}$ Pore volume of meso-pores: estimated by the BJH method. ${ }^{d}$ Major mesopore diameter peaks: estimated from adsorption branch by the BJH method. ${ }^{e}$ Weight ratio: estimated by the ICP-AES analysis.

In contrast, the crystalline phases of zirconia were monoclinic and tetragonal for the $\mathrm{Z} 80 \mathrm{~N} / \mathrm{K}(T)$ composites with $80 \mathrm{wt} \%$ of amount of introduced zirconia as shown in Fig. 4d. These results indicate that the excessive zirconium component was crystallized outside the mesoporous space of KIT- 6 as in the case of $\mathrm{Z} 50 \mathrm{P} / \mathrm{K}(600$ and 800$)$. The BJH plots of the $\mathrm{Z} 20 \mathrm{~N} / \mathrm{K}(T)$, $\mathrm{Z} 50 \mathrm{~N} / \mathrm{K}(T)$, and $\mathrm{Z} 80 \mathrm{~N} / \mathrm{K}(T)$ are displayed in Fig. S2. $\dagger$ The diameter peaks of the meso-pores of the $\mathrm{Z} 20 \mathrm{~N} / \mathrm{K}(T), \mathrm{Z} 50 \mathrm{~N} / \mathrm{K}(T)$ were 7.1-8.2 nm, while the $\mathrm{Z} 80 \mathrm{~N} / \mathrm{K}(T)$ sample showed two meso-pore diameter peaks as summarized in Table 3, similar to the results for the $\mathrm{Z} 50 \mathrm{P} / \mathrm{K}(T)$ sample. From the XRD analysis, the $\mathrm{Z} 80 \mathrm{~N} / \mathrm{K}(T)$ and $\mathrm{Z50P} / \mathrm{K}(T)$ consisted of monoclinic and tetragonal phases. Accordingly, we consider that the zirconia crystallized outside the KIT- 6 is monoclinic and possesses meso-pores that are smaller than those of KIT-6.

Effect of pore size of non-ordered mesoporous silica. We have studied how the pore diameter size of non-ordered mesoporous silica (Q- $M$ silica) used as a template affects the synthesis of $\mathrm{ZrO}_{2} / \mathrm{SiO}_{2}$ composites (Z20N/Q- $M$ and $\mathrm{Z} 50 \mathrm{~N} / \mathrm{Q}-M$ ). The physical properties of these $\mathrm{ZrO}_{2} / \mathrm{SiO}_{2}$ composites and of the obtained Q- $M$ silica samples are summarized in Table 4, and their pore size distributions (BJH plot) are shown in Fig. S3.† The order of $d_{\text {meso-pore }}$ of the obtained Q- $M$ samples at $800{ }^{\circ} \mathrm{C}$ was as follows: $\mathrm{Q}-50>\mathrm{Q}-30>\mathrm{Q}-10>\mathrm{Q}-3$. In addition, the $d_{\text {meso-pore }}$ of Q-3 was below $2 \mathrm{~nm}$ and Q-10 silica exhibited several pore diameter peaks. The $S_{\mathrm{BET}}, V_{\mathrm{pore}}$, and $V_{\text {meso-pore }}$ of Z20N/Q- $M$ and Z50N/Q- $M$ composites with 3, 10, and 30 of $M$ were smaller than those of each Q- $M$ silica. In contrast, for the composites using Q-50 silica, the $S_{\mathrm{BET}}$ values were larger and

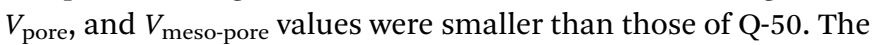
pore size distribution of the composites varied with the introduction of the zirconium component, implying that the formation of meso-pores derived from zirconia particles exist outside and inside of the silica.

For the $\mathrm{Z} 20 \mathrm{~N} / \mathrm{Q}-M(M=3,10,30)$ composites, the $\mathrm{SiO}_{2}$ and tetragonal zirconia phases were observed, while a small amount of the monoclinic phase was also present for the Z20N/Q-50 composite (Fig. S4a †). Furthermore, the Z50N/Q- $M(M=3,10$, $30,50)$ composites consisted of monoclinic and tetragonal phases (Fig. S4b $\uparrow$ ). Additionally, we found that the fraction of the tetragonal phase was decreased with increasing Q- $M$ pore size. Furthermore, the crystallinity of the zirconia component in each composite was higher compared to the case using the synthesized KIT-6, K(600), shown in Fig. 4b and c. Based on these results, we conclude that the pore size of the silica template affects the synthesis process of zirconia more significantly than the Zr-O-Si linkages effect. Namely, an increase in the pore size of the silica leads to the significant growth of

Table 5 Physical properties of $\operatorname{tZN}(T)$ and $r Z N(T): T=400,600,800$

\begin{tabular}{|c|c|c|c|c|c|c|}
\hline Sample & $S_{\mathrm{BET}}{ }^{a} / \mathrm{m}^{2} \mathrm{~g}^{-1}$ & $V_{\text {pore }}^{b} / \mathrm{cm}^{3} \mathrm{~g}^{-1}$ & $V_{\text {meso-pore }}{ }^{c} / \mathrm{cm}^{3} \mathrm{~g}^{-1}$ & $d_{\text {meso-pore }}{ }^{d} / \mathrm{nm}$ & $\mathrm{ZrO}_{2} /\left(\mathrm{ZrO}_{2}+\mathrm{SiO}_{2}\right)^{e} / \mathrm{wt} \%$ & $\begin{array}{l}\text { Crystallite size of } \mathrm{ZrO}_{2} \\
(h k l) \text {-phase } / / \mathrm{nm}\end{array}$ \\
\hline $\operatorname{tZN}(400)$ & 301 & 0.22 & 0.16 & $<2$ & 89 & n.d. ${ }^{g}$ \\
\hline $\operatorname{tZN}(600)$ & 260 & 0.23 & 0.19 & $<2$ & 90 & n.d. ${ }^{g}$ \\
\hline $\operatorname{tZN}(800)$ & 185 & 0.19 & 0.17 & $<2$ & 95 & $6.3\left(\begin{array}{lll}1 & 0 & 1\end{array}\right)-\mathrm{T}$ \\
\hline $\mathrm{rZN}(400)$ & 82 & 0.26 & 0.26 & 5,14 & 100 & $6.6\left(\begin{array}{lll}-1 & 1 & 1\end{array}\right)-\mathrm{M}, 12.0\left(\begin{array}{lll}1 & 0 & 1\end{array}\right)-\mathrm{T}$ \\
\hline $\mathrm{rZN}(600)$ & 32 & 0.26 & 0.26 & $4,21,33$ & 100 & $15.2\left(\begin{array}{lll}-1 & 1 & 1\end{array}\right)-\mathrm{M}, 17.4\left(\begin{array}{lll}1 & 0 & 1\end{array}\right)-\mathrm{T}$ \\
\hline $\mathrm{rZN}(800)$ & 12 & 0.18 & 0.18 & $4,24,44$ & 100 & $29.6\left(\begin{array}{lll}-1 & 1 & 1\end{array}\right)-\mathrm{M}$ \\
\hline
\end{tabular}

${ }^{a}$ BET specific surface area. ${ }^{b}$ Total pore volume: estimated at $0.99 P / P_{0} .{ }^{c}$ Pore volume of meso-pores: estimated by the BJH method. ${ }^{d}$ Major mesopore diameter peaks: estimated from adsorption branch by the BJH method. ${ }^{e}$ Weight ratio: estimated by the ICP-AES analysis. ${ }^{f}$ M: monoclinic, T: tetragonal. ${ }^{g}$ Not detected the clear diffraction peak. 
zirconia particles, resulting in the formation of the monoclinic phase.

\section{Removal of silica component}

The pure zirconia samples with the removal of the silica component, $\operatorname{tZN}(T)$, were synthesized by the alkaline treatment of $\mathrm{Z} 50 \mathrm{~N} / \mathrm{K}(T)$ using the KOH solution. When a similar treatment was conducted for the rZN(600) zirconia samples synthesized by the thermal decomposition method, there were no changes of the crystalline phase, $S_{\mathrm{BET}}, V_{\text {pore }}, V_{\text {meso-pore, }}$ and $d_{\text {meso-pore }}$, implying that the $\mathrm{KOH}$ solution cannot dissolve the zirconia. The physical properties of $\operatorname{tZN}(T)$ and $\operatorname{rZN}(T)$ with the calcination temperatures of $400{ }^{\circ} \mathrm{C}, 600{ }^{\circ} \mathrm{C}$, and $800{ }^{\circ} \mathrm{C}(T)$ based on the $\mathrm{N}_{2}$ ad-desorption, ICP-AES, and XRD analyses are summarized in Table 5. It was found that ca. $10 \mathrm{wt} \%$ of the KIT-6 silica component remained in the $\operatorname{tZN}(T)$ according to the results of the ICP-AES analysis. Upon increasing the calcination temperature, the $S_{\mathrm{BET}}$ of each zirconia was increased. We note that $\operatorname{tZN}(T)$ exhibited much larger $S_{\mathrm{BET}}$ values than those of $\operatorname{rZN}(T)$; the $S_{\mathrm{BET}}$ of tZN(800) was $185 \mathrm{~m}^{2} \mathrm{~g}^{-1}$, while the $S_{\mathrm{BET}}$ of $\mathrm{rZN}(800)$ was $12 \mathrm{~m}^{2} \mathrm{~g}^{-1}$. By contrast, there were no distinct differences in the $V_{\text {pore }}$ and $V_{\text {meso-pore }}$ between $\operatorname{tZN}(T)$ and $\operatorname{rZN}(T)$.

The XRD patterns of $\operatorname{tZN}(T)$ and $\operatorname{rZN}(T)$ with the calcination temperatures of $400{ }^{\circ} \mathrm{C}, 600{ }^{\circ} \mathrm{C}$, and $800{ }^{\circ} \mathrm{C}$ are displayed in Fig. 5. For the $\operatorname{tZN}(T)$ samples, the broad diffraction peak assigned to amorphous zirconia was observed for the tZN(400) and $\mathrm{tZN}(600)$; tZN(600) possessed tetragonal phase slightly. This was similar to the observations for Z50N/K(400) and Z50N/

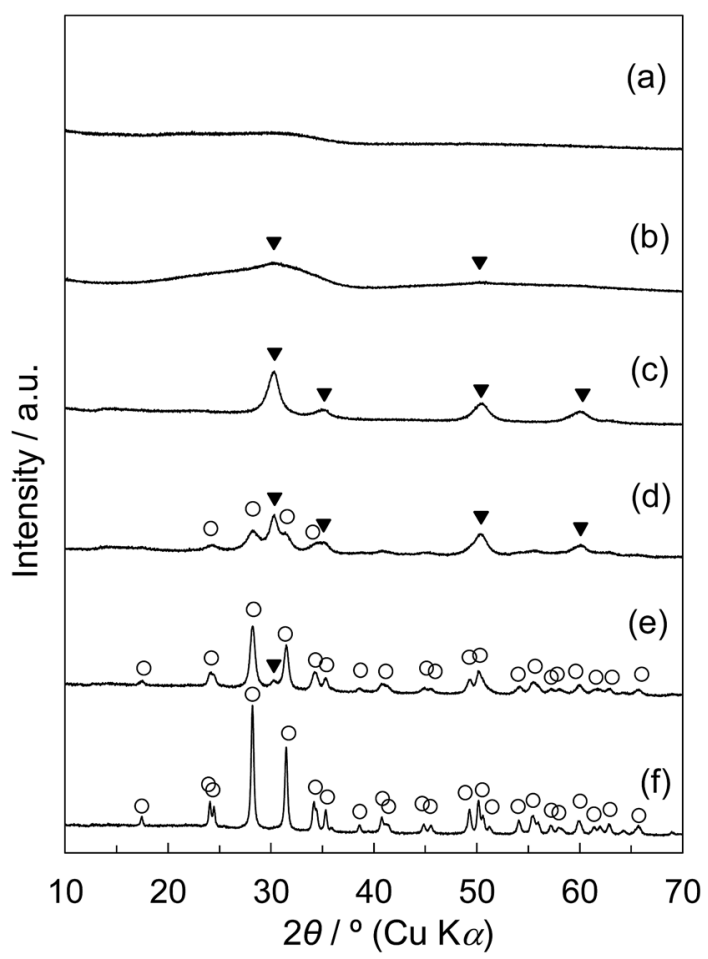

Fig. 5 Wide-angle XRD patterns of (a) tZN(400), (b) tZN(600), (c) tZN(800), (d) $r Z N(400)$, (e) $r Z N(600)$, and (f) $r Z N(800)$ : (O) $\mathrm{ZrO}_{2}-$ monoclinic, ( $\boldsymbol{\nabla}) \mathrm{ZrO}_{2}$-tetragonal.
$\mathrm{K}(600)$. For tZN(800), the diffraction peaks attributed to the tetragonal phase became sharper; however, the monoclinic zirconia phase was not observed. Conversely, the $\operatorname{rZN}(400)$ and rZN(600) were mixed crystals of tetragonal and monoclinic zirconia, and the $\mathrm{rZN}(800)$ was pure monoclinic zirconia. The crystallite sizes of each $\mathrm{ZrO}_{2}$ phase determined using Scherrer's equation are summarized in Table 5. For the $\operatorname{rZN}(T)$ with the calcination temperatures of $400{ }^{\circ} \mathrm{C}, 600{ }^{\circ} \mathrm{C}$, and $800{ }^{\circ} \mathrm{C}$, the crystallite sizes of the (111) plane of monoclinic zirconia appearing ca. $28.2^{\circ}$ were $6.6 \mathrm{~nm}, 15.2 \mathrm{~nm}$, and $29.6 \mathrm{~nm}$, respectively. Furthermore, for the $\operatorname{rZN}(T)$ with the $T$ of $400{ }^{\circ} \mathrm{C}$ and $600{ }^{\circ} \mathrm{C}$, the crystallite sizes of the (101) plane of tetragonal zirconia appearing $c a .30 .5^{\circ}$ were $12.0 \mathrm{~nm}$ and $17.4 \mathrm{~nm}$, respectively. By contrast, for the $\operatorname{rZN}(T)$, the crystallite size of the (101) tetragonal phase, which can be identified only for the tZN(800), was $6.3 \mathrm{~nm}$.

Fig. 6 shows the Raman spectra of $\operatorname{tZN}(T)$ and $\operatorname{rZN}(T)$ with the $T$ of $400{ }^{\circ} \mathrm{C}, 600^{\circ} \mathrm{C}$, and $800^{\circ} \mathrm{C}$ and reference zirconia (JRC-ZRO$3)$. In the case of $\operatorname{tZN}(T)$, large differences were present in the obtained Raman spectra. For the $\operatorname{tZN}(400)$ and $\operatorname{tZN}(600)$, no remarkable band peaks appeared, implying that they were almost in the amorphous state (Fig. $6 \mathrm{a}$ and b). By contrast, the $\operatorname{tZN}(800)$ exhibited distinctive spectra derived from tetragonal zirconia (Fig. 6c). ${ }^{37,38}$ Considering the XRD analysis, we conclude that the $\operatorname{tZN}(800)$ certainly consists of tetragonal zirconia. In addition, for the $\operatorname{rZN}(400)$ and $\operatorname{rZN}(600)$, the band peaks attributed to monoclinic and tetragonal zirconia were observed (Fig. 6d and e). In contrast, the band peaks assigned to only monoclinic zirconia were observed for the $\mathrm{rZN}(800)$ and the reference zirconia (Fig. $6 \mathrm{f}$ and $\mathrm{g}$ ). These results indicate that the

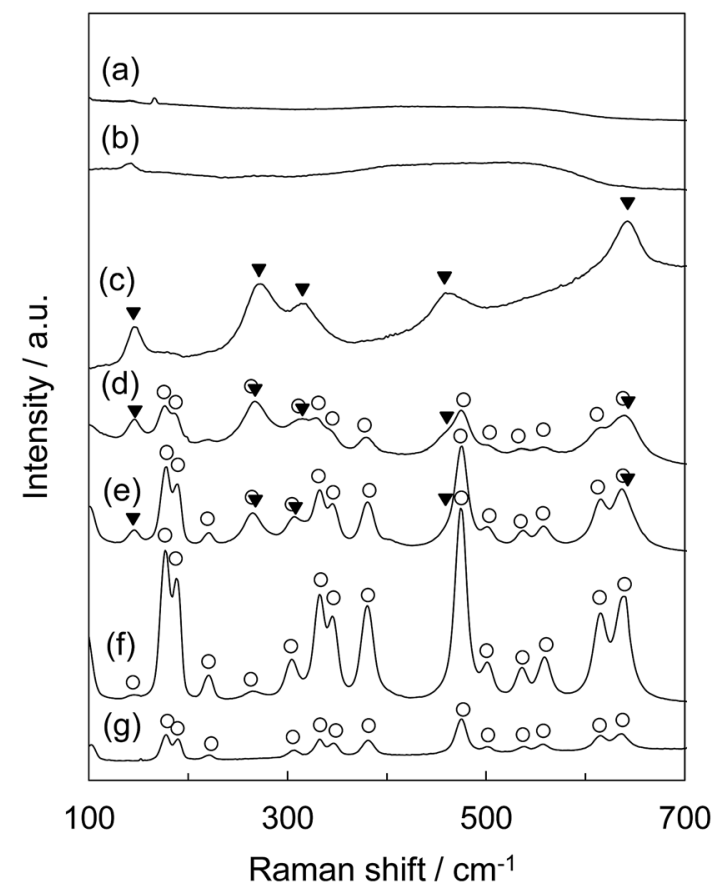

Fig. 6 Raman spectra of (a) tZN(400), (b) tZN(600), (c) tZN(800), (d) rZN(400), (e) rZN(600), (f) rZN(800), and (g) reference $\mathrm{ZrO}_{2}$ (JRC-ZRO3): (O) $\mathrm{ZrO}_{2}$-monoclinic, ( $\left.\mathbf{\nabla}\right) \mathrm{ZrO}_{2}$-tetragonal. 

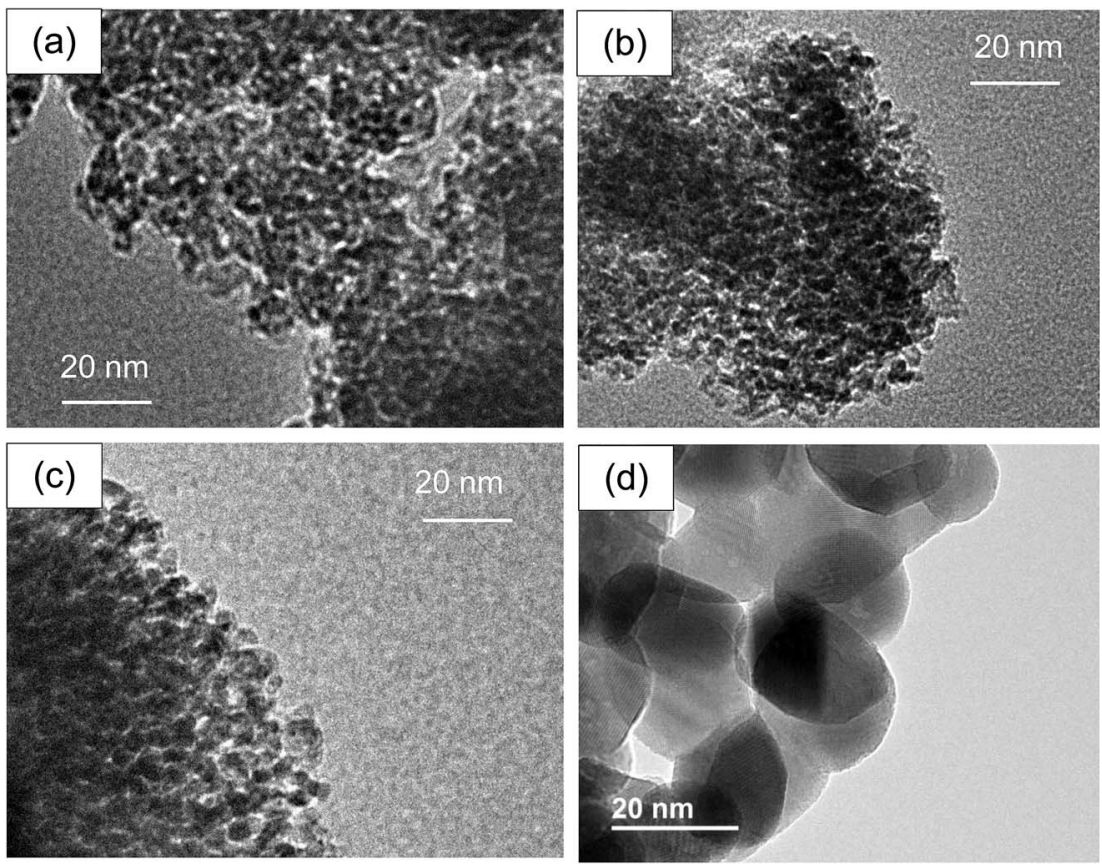

Fig. 7 TEM images of (a) tZN(400), (b) tZN(600), (c) tZN(800), and (d) rZN(600).

rZN(400) and rZN(600) were mixed crystals of tetragonal and monoclinic zirconia and the $\mathrm{rZN}(800)$ and reference zirconia consist of monoclinic zirconia, supporting the results of XRD analysis.

Fig. 7 represents the TEM images of $\operatorname{tZN}(T)(T=400,600$, $800)$ and rZN(600) samples. From these TEM images, the average sizes of zirconia particles were found to be $c a .23 \mathrm{~nm}$ for the $\mathrm{rZN}(600)$ and $2.0 \mathrm{~nm}, 2.2 \mathrm{~nm}$, and $4.5 \mathrm{~nm}$ for the $\operatorname{tZN}(400)$, $\operatorname{tZN}(600) \mathrm{tZN}(800)$, respectively. Upon increasing the calcination temperature, the synthesized zirconia particles were enlarged. However, it is noteworthy that the particle growth of the zirconia was apparently suppressed for the synthesis using meso-porous silica in comparison to the case for the synthesis by the thermal decomposition method.

As mentioned in Introduction section, monoclinic zirconia is considered to be stable up to $1170{ }^{\circ} \mathrm{C}$. In addition, the theoretical study proves that a metastable tetragonal zirconia can be stable below $650^{\circ} \mathrm{C}$ if the zirconia particle size is below $30 \mathrm{~nm} .^{3,4}$ Furthermore, it was reported that tetragonal zirconia can be synthesized using some special synthesis techniques. ${ }^{6-26}$ In contrast, the synthesis method reported in the present work, is a new method of the nanosized tetragonal zirconia from KIT-6 or commercial silica and from zirconyl nitrate without the high pressure synthesis conditions and special precipitating agents. Furthermore, the synthesized tetragonal zirconia possesses large specific surface area even after the final calcination at $800{ }^{\circ} \mathrm{C}$.

\section{Evaluation of catalytic activity for MeOH oxidation}

Finally, the synthesized $\operatorname{tZN}(T)$ have been used as a catalyst for $\mathrm{MeOH}$ oxidation. Fig. 8 shows the temperature dependence of $\mathrm{MeOH}$ conversion for $\mathrm{MeOH}$ oxidation over the $\operatorname{tZN}(T)$ catalysts that possess only tetragonal phase, and $\mathrm{rZN}(T)$ and JRC-ZRO-3 as reference catalysts that possess monoclinic and tetragonal phases. In the present work, the main reaction products were $\mathrm{CO}$ and $\mathrm{H}_{2} \mathrm{O}$ for the $\mathrm{MeOH}$ oxidation over all catalysts. We confirmed that $\mathrm{MeOH}$ can be oxidized to $\mathrm{CO}_{2}$ and $\mathrm{H}_{2} \mathrm{O}$ using $2 \mathrm{wt} \% \mathrm{Ag}$ catalysts supported by the synthesized zirconia (results are not shown). The addition of $\mathrm{Ag}$ component

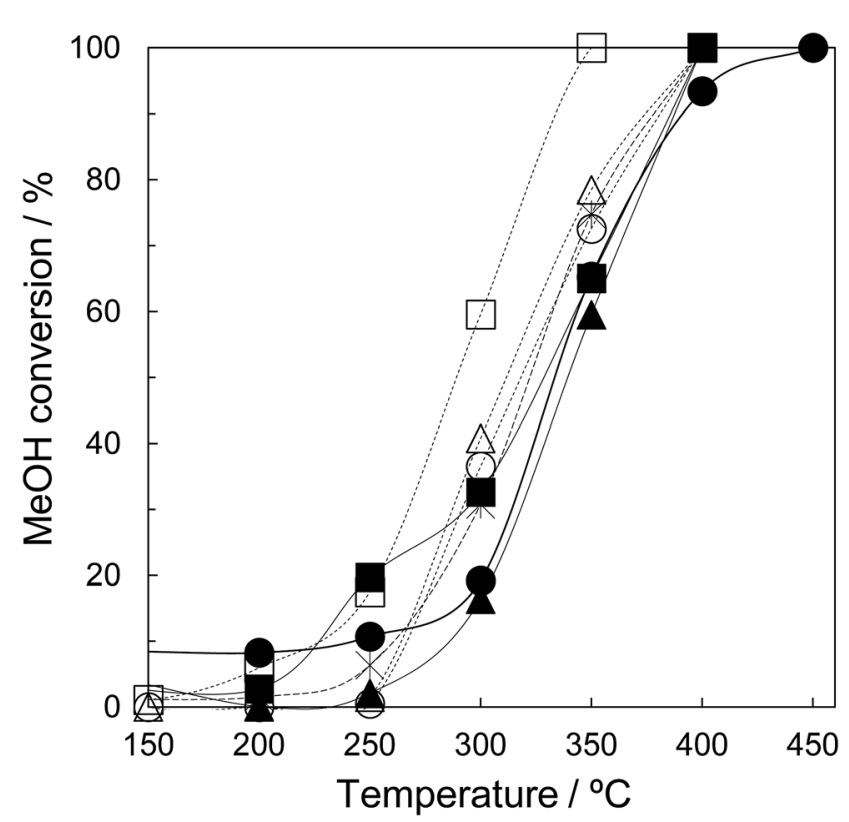

Fig. 8 Catalytic performance of various zirconia samples for $\mathrm{MeOH}$ oxidation: $(\triangle)$ tZN(400), (O) tZN(600), ( $\square) \operatorname{tZN}(800),(\mathbf{\Delta}) \mathrm{rZN}(400)$, (-) rZN(600), (回) rZN(800), (*) JRC-ZRO-3. Reaction conditions: 1000 ppm MeOH/air balance; W/F: $6.7 \mathrm{~g}_{\mathrm{cat}} \mathrm{h} \mathrm{L}_{\mathrm{MeOH}^{-1}}$. 
enhances the oxidation step of methoxy species to $\mathrm{CO}_{2}$ due to the formation of active oxygen species on $\mathrm{Ag}$ species. ${ }^{32}$ In addition, in situ Fourier Transform Infrared Spectroscopy (FTIR) demonstrates that the $\mathrm{MeOH}$ adsorption sites are on the zirconia support with high crystallinity. Therefore, to elucidate the adsorption property of $\mathrm{MeOH}$ on the synthesized zirconia, we have evaluated the catalytic property of zirconia for $\mathrm{MeOH}$ oxidation. Comparing the $\mathrm{MeOH}$ conversion at $300{ }^{\circ} \mathrm{C}$, the performance order of the $\operatorname{rZN}(T)$ catalysts was as follows: $\operatorname{rZN}(800)>\operatorname{rZN}(600)>\operatorname{rZN}(400)$. Among the $\operatorname{tZN}(T)$ catalysts, $\operatorname{tZN}(800)$ exhibited the highest performance and the $\mathrm{MeOH}$ conversion at $300{ }^{\circ} \mathrm{C}$ was $\mathrm{ca} .60 \%$. The $\mathrm{MeOH}$ conversions over $\operatorname{tZN}(400)$ and $\operatorname{tZN}(600)$ were $c a$. 40\%. The $\operatorname{tZN}(T)$ catalysts exhibited higher performance than $\operatorname{rZN}(T)$ catalysts and JRCZRO-3. This performance may be attributable to the larger surface area of $\operatorname{tZN}(T)$ than $\operatorname{rZN}(T)$. Additionally, we found that the higher the calcination temperature, the higher the catalytic performance of zirconia. Indeed, the $\mathrm{MeOH}$ conversion per the surface area for the zirconia catalysts was not constant, indicating that the crystallinity of zirconia affects the catalytic performance. In other words, an increase in the crystallinity of zirconia leads to the improvement of the dissociative adsorption performance of oxygen and the enhancement of the formation of active oxygen species on the zirconia surface, resulting in the high performance of zirconia for $\mathrm{MeOH}$ oxidation.

In the present work, the $\operatorname{tZN}(800)$ which consists of fine particles, possesses high specific surface area, and has only tetragonal phase was successfully synthesized. In addition, it was revealed that the $\operatorname{tZN}(800)$ exhibits excellent catalytic performance for $\mathrm{MeOH}$ oxidation compared to the conventional zirconium catalysts. Furthermore, we suggest that application of a tetragonal zirconia material with large surface area as a catalyst will be beneficial for various catalytic processes such as water-gas-shift reaction, $\mathrm{CO}_{2}$ methanation, and $\mathrm{MeOH}$ synthesis.

\section{Conclusions}

Synthesis of zirconia by the hard template method using KIT-6 mesoporous silica and the performance of such zirconia for catalytic combustion have been studied. Composites of tetragonal zirconia and silica were successfully synthesized by the decomposition of zirconia sources in the mesoporous space of KIT-6. The formation behavior of tetragonal zirconia depends on the zirconia sources, the pore size of mesoporous silica, the loading amount of zirconia sources, and calcination temperature. The crystallization of zirconia in the mesoporous space results in the formation of fine zirconia particles, leading to the formation of pure tetragonal zirconia crystalline phase instead of the monoclinic zirconia crystalline phase, as known to occur due to the crystallite size effect. Furthermore, the nanosized tetragonal zirconia possessing large BET specific surface was synthesized through the removal of the silica component in the zirconia-silica composite by the alkaline treatment. In addition, the catalytic performance of tetragonal zirconia materials for methanol oxidative decomposition have been evaluated. Among the zirconia catalysts prepared in the present study, the sample prepared by the hard template method and calcined at $800{ }^{\circ} \mathrm{C}$ exhibited the highest activity for $\mathrm{MeOH}$ oxidation. We conclude that the crystallinity of zirconia and a high BET specific surface area are both necessary to achieve a high catalytic activity for the $\mathrm{MeOH}$ oxidation reaction.

\section{Conflicts of interest}

There are no conflicts to declare.

\section{Acknowledgements}

This study was supported by the Cooperative Research Program of Institute for Catalysis, Hokkaido University, (Grant \#14B1009) and the authors would like to thank them for their support. Additionally, we are grateful to Prof. Koichi Eguchi, Kyoto University for their kind help with Raman spectroscopy analysis.

\section{Notes and references}

1 T. Yamaguchi, Catal. Today, 1994, 20, 199-218.

2 G. Štefanić, S. Musić and A. Sekulić, Thermochim. Acta, 1996, 273, 119-133.

3 R. C. Garvie, J. Phys. Chem., 1965, 69(4), 1238-1243.

4 R. C. Garvie, J. Phys. Chem., 1978, 82(2), 218-224.

5 G. S. A. M. Theunissen, J. S. Bouma, A. J. A. Winnubst and A. J. Burggraaf, J. Mater. Sci., 1992, 27, 4429-4438.

6 W. Stichert and F. Schüth, Chem. Mater., 1998, 10, 20202026.

7 M. Inoue, H. Kominami and T. Inui, Appl. Catal., A, 1993, 97, L25-L30.

8 H. S. Kil, S. H. Hwag, J. H. Ryu, D. Y. Lim and S. B. Cho, J. Ceram. Soc. Jpn., 2012, 120, 52-57.

9 S. Riaz, M. Bashir and S. Naseem, J. Sol-Gel Sci. Technol., 2015, 74, 275-280.

10 Y. Chang, C. Wang, T. Liang, C. Zhao, X. Luo, T. Guo, J. H. Gong and H. Wu, RSC Adv., 2015, 5, 104629-104634.

11 Q. W. Ge, X. P. Liu, G. Parada, S. K. Mallapragada and M. Akinc, Sci. Adv. Mater., 2014, 6, 2106-2114.

12 Q. Mahmood, A. Afzal, H. M. Siddiqi and A. Habib, J. Sol-Gel Sci. Technol., 2013, 67, 670-674.

13 F. Davar, A. Hassankhani and M. R. Loghman-Estarki, Ceram. Int., 2013, 39, 2933-2941.

14 N. B. Nayak, B. B. Nayak and A. Mondal, J. Am. Ceram. Soc., 2013, 96, 3366-3368.

15 M. C. Wang and H. J. Huang, Thermochim. Acta, 2013, 567, 93-99.

16 A. U. Maheswari, S. S. Kumar and M. Sivakumar, J. Nanosci. Nanotechnol., 2013, 13, 4409-4414.

17 V. G. Deshmane and Y. G. Adewuyi, Microporous Mesoporous Mater., 2012, 148, 88-100.

18 H. Saricimen, A. Ul-Hamid and A. Quddus, Prot. Met. Phys. Chem. Surf., 2015, 51, 803-811.

19 M. Salavati-Niasari, M. Dadkhah, M. R. Nourani and A. A. Fazl, J. Cluster Sci., 2012, 23, 1011-1017. 
20 X. L. Yan, N. Y. Lu, B. B. Fan, J. H. Bao, D. H. Pan, M. J. Wang and R. F. Li, CrystEngComm, 2015, 17, 6426-6433.

21 P. Wang, Z. D. Zhao, Z. D. Zhao, Z. D. Wang, S. X. Chen and G. R. Fan, BioResources, 2015, 10, 1271-1284.

22 L. Liu, J. C. Xue and X. P. Zhou, Nanosci. Nanotechnol. Lett., 2014, 6, 346-352.

23 S. Kurakaran, A. George and A. S. Nair, J. Indian Chem. Soc., 2014, 91, 47-52.

24 C. Sanchez, C. Boissire, D. Grosso, C. Laberty and L. Nicole, Chem. Mater., 2008, 20, 682-737.

25 J. N. Kondo and K. Domen, Chem. Mater., 2008, 20, 835-847.

26 R. Xu, W. Pang, J. Yu, Q. Huo and J. Chen, Chemistry of Zeolites and Related Porous Materials - Synthesis and Structure, John Wiley \& Sons (Asia) Pte., 2007.

27 F. Kleitz, S. H. Choi and R. Ryoo, Chem. Commun., 2003, 2136-2137.

28 B. Liu and R. T. Baker, J. Mater. Chem., 2008, 18, 5200-5207. 29 N. Suzuki, T. Kimura and Y. Yamauchi, J. Mater. Chem., 2010, 20, 5294-5300.

30 Q. Pan, A. Ramanathan, W. K. Snavely, R. V. Chaudhari and B. Subramaniam, Ind. Eng. Chem. Res., 2013, 52, 1548115487.
31 L. Gong, L. B. Sun, Y.H Sun, T. T. Li and X. Q. Liu, J. Phys. Chem. C, 2011, 115, 11633-11640.

32 N. Shimoda, S. Umehara, M. Kasahara, T. Hongo, A. Yamazaki and S. Satokawa, Appl. Catal., A, 2015, 507, 56-64.

33 I. Ro, Y. Liu, M. R. Ball, D. H. K. Jackson, J. P. Chada, C. Sener, T. F. Kuech, R. J. Madon, G. W. Huber and J. A. Dumesic, ACS Catal., 2016, 6, 7040-7060.

34 T. Witoon, J. Chalorngtham, P. Dumrongbunditkul, M. Chareonpanich and J. Limtrakul, Chem. Eng. J., 2016, 293, 327-336.

35 S. Tada, F. Watanabe, K. Kiyota, N. Shimoda, R. Hayashi, M. Takahashi, A. Nariyuki, A. Igarashi and S. Satokawa, J. Catal., 2017, 351, 107-118.

36 Y. Azuma, K. Nogami and N. Ohshima, J. Ceram. Soc. Jpn., 1992, 100, 646-651.

37 J. A. Muñoz Tabares and M. J. Anglada, J. Am. Ceram. Soc., 2010, 93, 1790-1795.

38 S. Pradhan, V. Sahu and B. G. Mishra, J. Mol. Catal. A: Chem., 2016, 425, 297-309. 